\title{
Anatomy of the hyoid skeleton of the rock dove (Patagioenas livia)
}

\author{
Fatma A. Al-Nefeiy $1^{1}$ and Bedoor A. Alahmary ${ }^{2}$ \\ ${ }^{1}$ Biology Department, Faculty of Science, King Abdulaziz University, Jeddah, Saudi Arabia \\ ${ }^{2}$ Biology Department, Faculty of Science, Taif University, Saudi Arabia
}

\begin{tabular}{|l|l|}
\hline $\begin{array}{l}\text { Article history } \\
\text { Received: 13 Feb, 2016 } \\
\text { Revised: 9 Mar, 2016 } \\
\text { Accepted: 11 Mar, 2016 }\end{array}$ & $\begin{array}{l}\text { Abstract } \\
\text { Twenty five adult specimens of the Rock dove were used in the present study. The } \\
\text { general histology and scanning electron microscopic investigations. The hyoid } \\
\text { skeleton consists of three axial unpaired elements and a paired hyoid horn. The axial } \\
\text { skeleton comprises an anterior os paragoossale, a middle os basihyale, an a posterior } \\
\text { os urohyale. The paired hyoid horn consists of os ceratobranchiale and os } \\
\text { epibranchiale. The hyoid horns are curved dorso-laterally reaching the posterior side of } \\
\text { the skull. The hyoid skeleton has Joint and ligaments between basihyal, } \\
\text { ceratobranchials, and urohyal to allow the ceratobranchials and the urohyal to rotate } \\
\text { from dorsal to ventral, from lateral to medial and from rostral to caudal, and to rotate } \\
\text { along their axes. } \\
\text { Keywords: The rock dove; anatomy; hyoid skeleton; scanning electron microscope }\end{array}$ \\
\hline
\end{tabular}

To cite this article: Al-Nefeiy1 FA and BA Alahmary, 2016. Anatomy of the hyoid skeleton of the rock dove (Patagioenas livia). Res. Opin. Anim. Vet. Sci., 6(2): 40-46.

\section{Introduction}

The anatomical structure of the avian feeding system shows a great diversity among different birds. Studying the various components of this system in accordance with their feeding habits leads to make the coordination of movements and their elements well understandable. Consequently, the functional morphological study of the avian feeding system includes an attempt to describe the tongue and larynx. In the literature, many attempts were done to describe the osteology and myology of the cranium, jaw apparatus and lingual systems of some birds (Burton, 1974; Bhattacharyya, 1980; Zweers, 1982). The jaw apparatus plays a very important role in selecting or rejecting, transporting and manipulating the food towards the gullet. Chickens, pigeons, ducks, passerine species, parrots, kestrel and some marine birds markedly attracted the attention of many investigators
(Richards \& Bock, 1973; Bock, 1974; Burton, 1974; Zweers, 1974, 1982; Zweers et al., 1977; Battacharyya, 1980; Homberger, 1986; Shawki, 1995; Shawki \& AlJalaud, 1994a,b; Shawki \& Abdel-Rahmaan, 1998; Shawki \& Ismail, 2006). Parchami and Dehkordi (2013) studied light and electron microscopy of the tongue in White eared bulbul (Pycnonotus leucotis). Battacharyya (1980) described the morphology of the jaw of the common pigeon. Zweers (1982) studied the functional anatomy of the feeding apparatus of the pigeon. Bock (2001) studied the functional morphology of the feeding apparatus of the woodpecker. Korzoun et al. (2001) studied morphofunctional features of the bill and hyoid apparatus of Turacos and their relations to feeding habits. Shawki and Ismail (2006) gave full description of the hyoid skeleton of the common moorhen. Erdogan et al. (2012) discussed anatomical and histological structure of the tongue in the Chukar partridge (Alectoris chukar). Igwebuike and Eze (2010)

\footnotetext{
*Corresponding author: Fatma A Al-Nefeiy1, Biology Department, Faculty of Science, King Abdulaziz University, Jeddah, Saudi Arabia
} 
described the anatomy of the oropharynx and tongue of the African pied crow in relation to feeding adaptations. Elsheikh and Al-Zahaby (2014) discussed the light and scanning electron microscopy of tongue in the hooded crow (Corvus corone cornix). The hyoid skeleton provides sites for muscle attachments, fascia and salivary glands. The mode of action of the different elements of this system is discussed. The present study of the hyoid skeleton of pigeons attempted to correlate the structure of the different components with the mechanical performance during the feeding process. A full description of the structural elements of the hyoid skeleton, as well as their articulations and ligaments, is given and discussed.

\section{Materials and Methods}

\section{Animals}

Twenty five adult specimens of the rock dove were used in the present study. Birds were brought alive to the laboratory, and then were killed by concentrated $(95 \%)$ chloroform inhalation. The specimens were dissected under the binocular with camera Lucida attachment (Roger Vaughan, England).

\section{Preparation and staining of skeletal elements}

The method of Minoru (1976) was used to differentiate between the bone and cartilage. The skeletal elements were carefully dissected from the surrounding muscles, gland and fascia. Then, skeletal elements were fixed in $95 \%$ ethanol for 4 days, then were placed in acetone for one day to remove fats. The samples were stained for 2-3 days in following staining solution at $37^{\circ} \mathrm{C} ; 0.3 \%$ alcian blue in $70 \%$ ethanol, $0.1 \%$ alizarin red in $95 \%$ ethanol, acetic acid and $70 \%$ ethanol. The stained samples were washed in distilled water and cleared in $1 \%$ aqueous solution of $\mathrm{KOH}$ for $12-48 \mathrm{~h}$. The samples were placed in aqueous solution of $20 \%$ glycerin containing $1 \% \mathrm{KOH}$ for $1-5$ days. Finally, the specimens were cleared through 50 and $80 \%$ glycerin, and stored in $100 \%$ glycerin.

\section{Preparation of specimens for light microscopic investigation}

For histological examination, the method of Humason (1972) was used. The tongue and larynx were fixed in Bouin's solution for about 12-24 h, and washed in $70 \%$ ethyl alcohol. Dehydration was done through ascending series of $70-95 \%$ ethyl alcohol (1-2 h), followed by two changes in absolute ethyl alcohol for 2 h. Specimens were cleared in ethyl alcohol and xylene (v/v ; 1:1 ) for 1-2 h, and then by absolute xylene (2-3 h), and finally embedded in paraffin wax. Serial sections of $6 \mu \mathrm{m}$ thickness were prepared according to normal histological techniques for staining with HaematoxylinEosin method. Sections were dehydrated through 90, 95 and $100 \%$ ethyl alcohol, then cleared in xylene and mounted in Canada Balsam.

\section{Preparation of specimens for scanning electron microscopic (SEM)}

The tongue was cut into small pieces, and directly fixed in $5 \%$ glutraldehyde in cacodylate buffer for at least $48 \mathrm{~h}\left(\mathrm{pH}, 7.2\right.$ at $\left.4^{\circ} \mathrm{C}\right)$ then washed three times in $0.1 \%$ cacodylate buffer. The specimens were post-fixed in a cacodylate buffered solution of $1 \%$ osmium tetroxide for $2 \mathrm{~h}$ at $37^{\circ} \mathrm{C}$. The specimens were washed in the same buffer three times, dehydrated and then infiltrated with amyl acetate for two days. The drying of specimens is accomplished by the critical point drying using liquid carbon dioxide, mounted and sputtercoated with gold. The specimens were examined under scanning electron microscope (JSM-6390-LA).

\section{Results}

\section{The hyoid skeleton (Fig. 1\&2)}

The hyoid skeleton consists of three axial unpaired elements and a paired hyoid horn. The axial skeleton comprises anterior os paraglossale, a middle os basihyale, and a posterior os urohyale. The paired hyoid horn consists of os ceratobranchiale and os epibranchiale. The hyoid horns are curved dorsolaterally reaching the posterior side of the skull.

\section{Os paraglossale (Fig. 3A)}

It is the most anterior and longest unpaired skeletal element which supports the free portion of the tongue. It is pointed anteriorly and branched posteriorly. Histological investigation revealed that it consists of hyaline cartilage (Fig. 4). It provides sites of attachment for intrinsic lingual muscles.

\section{Os basihyale (Fig. 3B\&8)}

It lies posterior to the paraglossale, composed of an anterior bony portion, which has a dorsal longitudinal crest and posterior cartilaginous portion, and connected to unpaired urohyale. Scanning electron microscope (Fig. 8) revealed the dorsal and lateral surfaces of basihyale.

\section{Os urohyale (Fig. 3C)}

It is the most posterior unpaired skeletal element composed of an anterior cylindrical bony part and a short posterior cartilaginous one. It supports the anterior region of the preglottal area.

\section{Os ceratobranchiale}

The Os ceratobranchiale represents the proximal rod-like bony skeletal element of the hyoid horn. The ceratobranchiale is articulated anteriorly with the basihyale and urohyale through a cap of hyaline cartilage 


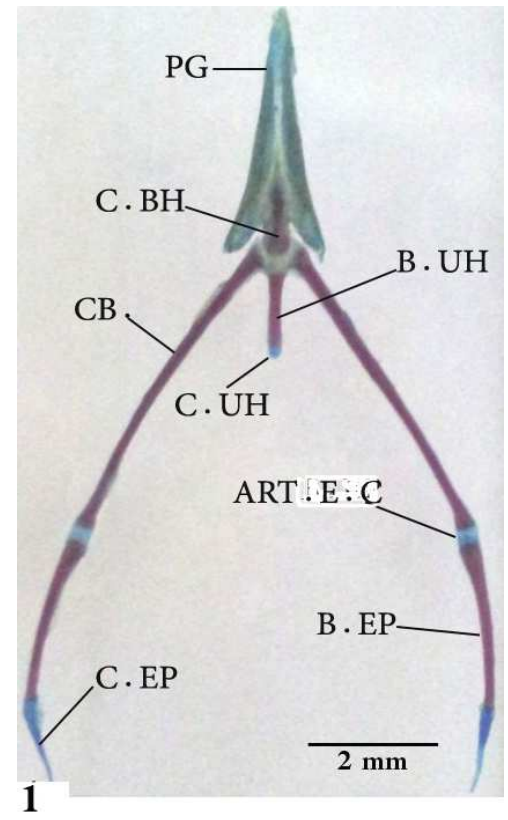

Fig. 1: Photomicrograph of dorsal view of the hyoid skeleton of the rock dove. PG: Paraglossale, C. BH: cartilagenous basihyale, B.BH: bony basihyale, B.UH: Bony urohyalis, C.UH: cartilagenous urohyalis, CB: Ceratobranchiale, ART.E.C: Articulation epi-ceratobranchialis, B.EP: bony epibranchial, C.EP: cartilaginous epibranchial

and posteriorly with Os epibranchiale through a cartilaginous bridge. The bony ceratobranchiale provides sites of origin for the intrinsic lingual muscles.

\section{Os epibranchiale}

The Os epibranchiale consists of a proximal bony element, epibranchiale I, and a distal cartilaginous, epibranchiale II. The bony epibranchiale I is cylindrical structure which articulates anteriorly with the ceratobranchiale and posteriorly with the cartilaginous epibranchiale II. The posterior half of the epibranchiale I is curved medio-dorsally. It provides the site of origin for the muscle branchiomandibularis. The epibranchiale II curves dorso-laterally to lies very close to the dorsolateral side of the skull. The epibr-anchiale II also provides the site of origin for the muscle branchiomandibularis.

\section{Joints between skeletal elements of the tongue} Joint between paraglossale and basihyale (Fig. 5)

Histologically, the articular surface of the basihyale fits closely with that of the paraglossale (Fig.5). This joint only allows rotation of the paraglossale along the longitudinal axis of the convex basihyale articular surface. This means that the tongue is allowed to roll to the left or right over the medial length axis of the
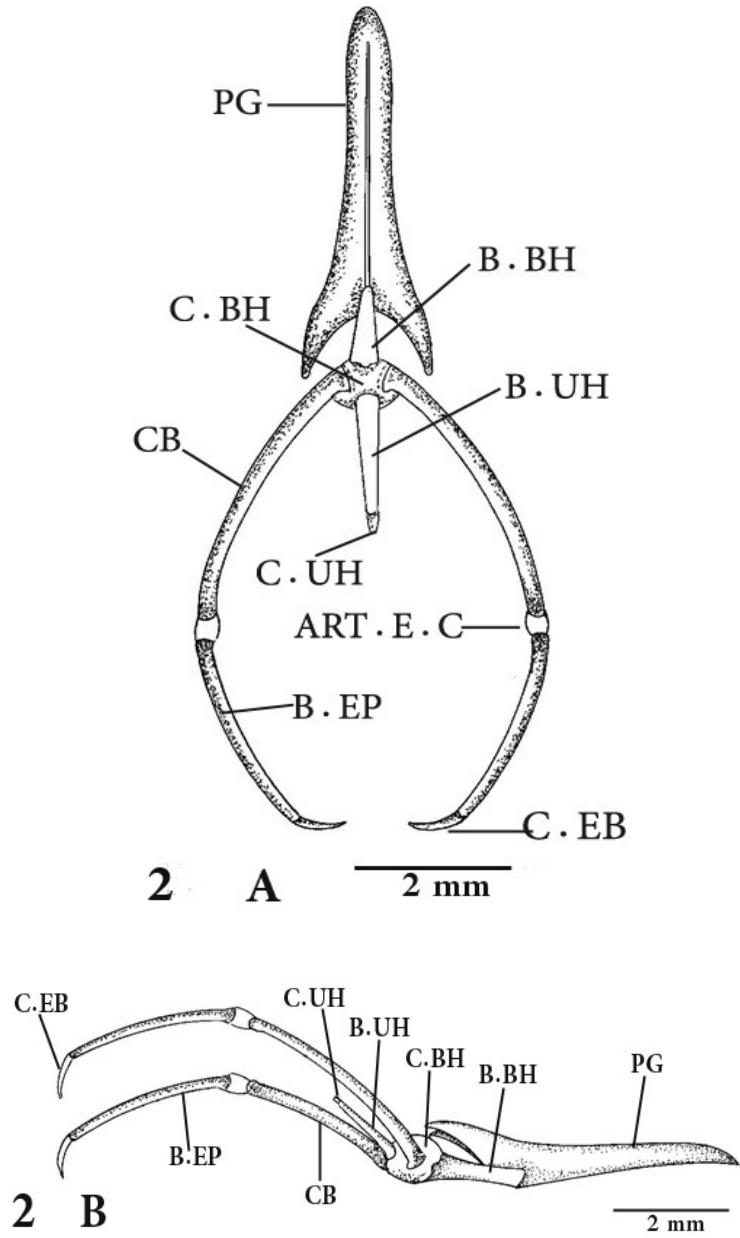

Fig. 2: Diagram of dorsal view (A) and lateral view (B) of the hyoid skeleton of the rock dove. PG: paraglossale, C. BH: cartilagenous basihyale, B. BH: bony basihyale, B.UH: bony urohyalis, C.UH: cartilagenous urohyalis, CB: ceratobranchiale, ART.E.C: Articulation epi-ceratobranchialis, B.EP: bony epibranchial, C. EP: cartilaginous epibranchial.

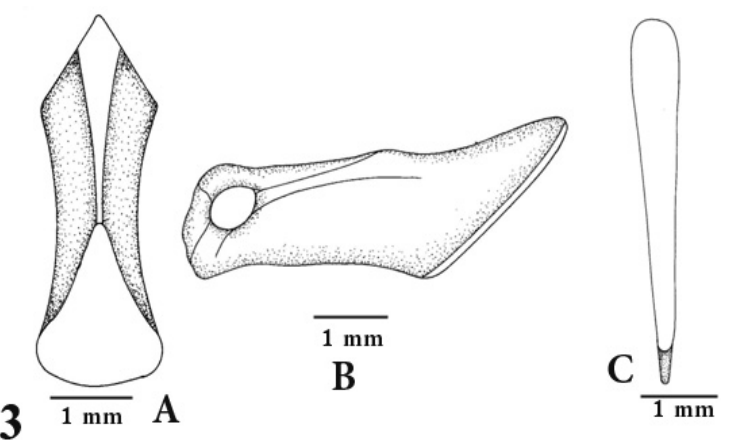

Fig. 3: Diagrams of (A) dorsal and (B) lateral views of the basihyale and (C) dorsal view of urohyale of the rock dove. 


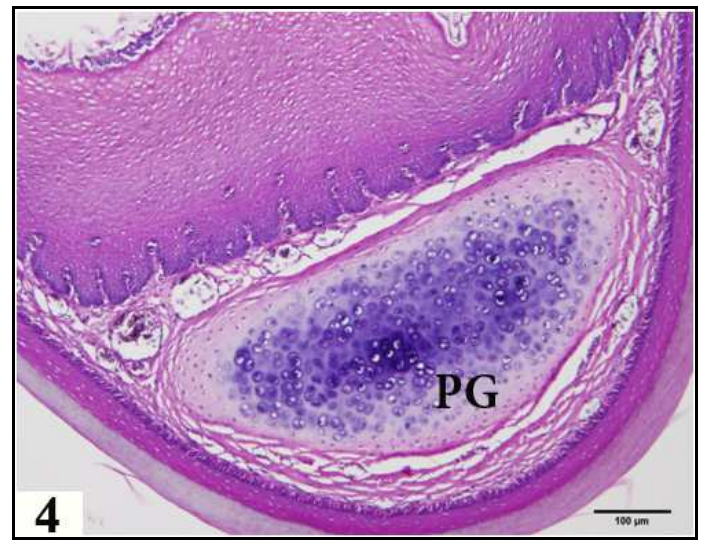

Fig. 4: Photomicrograph of a transverse section through the anterior-third of the free portion of the tongue of Rock dove showing that the paraglossale (PG) is composed of hyaline cartilage. (H.\&E., 200x)

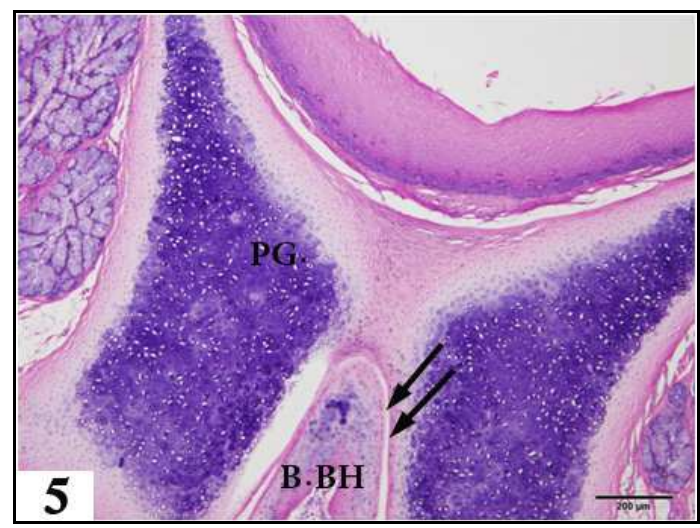

Fig. 5: Photomicrograph of a transverse section through the posterior part of the free portion of the tongue of Rock dove showing the paraglossales (PG) and articulation paraglosso-basihyali (double arrows) (H.\&E., 100x). B.BH: bony basihyale

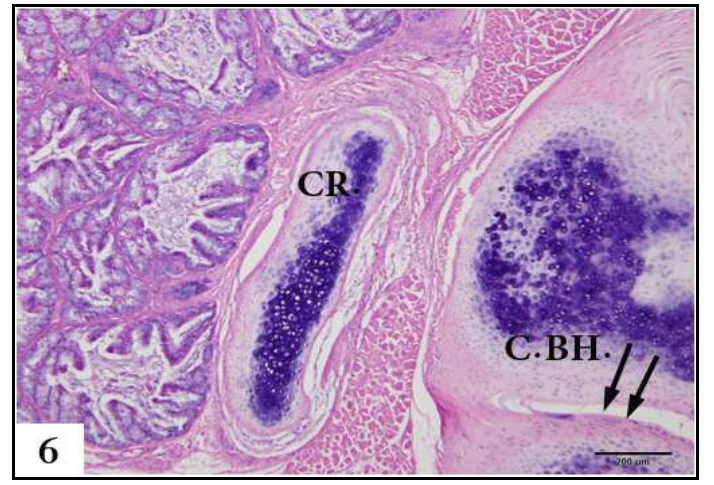

Fig. 6: Photomicrograph of a transverse section through the preglottal area of the tongue of Rock dove showing the Ceratobranchiale (CR) and articulation ceratobasihyalis ( double arrows) (H.\&E., 40x). C.BH: cartilagenous basihyale

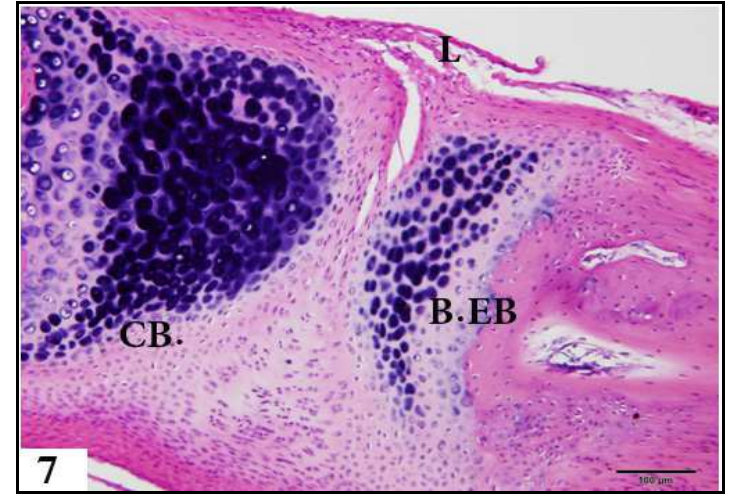

Fig. 7: Photomicrograph of a longitudinal section of articulatio epi-ceratobranchiale showing the presence of space between the articular surface of the epibranchiale (B.EP) and that of the ceratobranchiale $(\mathrm{CB})$ and the articular ligament (L.) $(\mathrm{H} \& \mathrm{E}, 100 x)$

basihyal articular surface, while only a slight oblique rotation of the tongue from left to right is possible. To a large extent, both articulation surfaces are held in position by two medially and longitudinally running ligaments. These ligaments are dorsal and ventral basihyo-paraglossale. The first ligament runs between the rostral end of the dorsal ridge of the basihyale and the lingual mucosa, just dorsal to the bifurcation of the paraglossale. The second ligament runs between the rostral end of the ventral basihyale ridge and the perichondrium of the paraglossale, just rostral to the anastomosis of the left and right paraglossale wings. The basihyo-paraglossale dorsal acts elastically against the ventral rotation of the paraglossale because of the ligamentous connection with the lingual cartilage via the dorsal lingual skin. The ventral ligament acts more abruptly as a stop against a dorsal rotation of the paraglossale. This joint allows firm caudalward push of the paraglossale onto the basihyale. The joint simultaneously allows the paraglossale to roll longitudinally and so rotate slightly obliquely over the basihyale joint surface from left to right and back.

Joint between basihyal, ceratobranchials and urohyal

The cup-and-saucer-like articulation surfaces of the ceratobranchials and urohyal with the basihyal allow the ceratobranchials and the urohyal to rotate from dorsal to ventral, from lateral to medial and from rostral to caudal, and to rotate along their axes. Histological investigation revealed that there is a convex articulation surface of the ceratobranchial (Fig. 6) which vertically elongated and looks double-headed. Basihyoceratobranchiale is placed on the basihyal just lateroventrorostral to the joint on the basihyal, to the lateroventrorostral side of the rostral club-shaped end of the 
ceratobranchial, thus restricting dorsal and medial movements of the ceratobranchial. The second ligament runs similarly in a more dorsal position. The third ligament runs from the ventrolateral side of the urohyal just caudal to the attachment of the previous ligaments, to the ventrolateral side of theceratobranchial, allowing only restricted dorsal, lateral, and ventral movement of the ceratobranchiale.

Dorsoventral movement is also restricted in the joint between the urohyal and the basihyal by a vertically elongated articulation surface and by the presence of two ligaments. These ligaments are basilyourohyale dorsal and ventral. The dorsal ligament runs from the dorsal ridge of the basihyal just rostrally from the basihyal joint surface to the dorsal side of the urohyal just caudal to the articulation head. Left-right movement is allowed by the joint surfaces but is restricted by the presence of the two ceratobranchials and the two urohyoceratobranchiale ligaments. Meanwhile the basihyal-urohyal joint and ligaments can clearly resist both heavy push and strong pull from caudal and rostral. Also "lever" action from dorsal or ventral will be resisted by the urohyal. The bilateral basihyal-ceratobranchial joints resist caudolateral push from both ceratobranchials and rostral push from the basihyal.

\section{Joint between ceratobranchial and epibranchial}

The joint is a paired articulation between the paired hyoid horns. Each of which connects both of the bony part proximal end of the epibranchial with the distal end of the Osceratobranchiale. Both ends are enveloped by a cartilaginous capsule leaving a small space between them to form a synchondrosis (Fig. 7). Scanning electron microscope shows the articulation of the ceratobranchiale and epibranchial. Joints of synchondrosis of the hyoid skeleton have collagenous fibers (Fig. $9 \& 10$ ).

\section{Discussion}

There is a correlation between the structural components of the lingual apparatus and its mechanical movements. The mechanical movement of the avian tongue is performed by the action of the lingual muscles which is governed by the associated structures, joints and ligaments. The hyoid skeleton, the main support of the tongue, allows sites for attachment of the lingual muscles, which are in turn the generator of forces. In addition, the hyoid skeleton anchors the lingual salivary glands, which act as hydraulic structures and are integrated with the tongue movements. A morphological study of the hyoid skeleton may also include the joints and organized connective tissues, i.e., the articular ligaments (Shawki\& Ismail, 2006). The different structural elements of the hyoid skeleton move along each other, resulting in the mobility of the tongue itself. The present results showed that the hyoid skeleton is a well developed in rock dove like the hyoid skeleton was found in the parrot (Homberger, 1986), in white throated kingfisher (Halcyon smyrnensis) and common buzzard (El-Beltagy, 2013) and in the Egyptian black kite (Shawki, 1995). The paraglossale forms the longest and elongated, unpaired arrow-shaped skeletal support of the free portion of the tongue in the rock dove it is very similar to the paraglossal of some species of common moorhen, Herring gull, chicken and the golden eagle (Homberger \& Meyers, 1989; Shawki, \& Al-Jalaud, 1994b; Shawki \& Ismail, 2006; Parchami \& Fatahian, 2010). The surface structures of the paraglossale usually indicate attachment sites for muscle or ligaments. It is interesting to notice that the paraglossale of rock dove which supports the free portion of the tongue is consisting of hyaline cartilage. Comparing the characteristics of the different types of cartilage, the elastic cartilage has a great ability of bending than the fibrous one, while the latter is able to bend more than the hyaline cartilage can do. Meanwhile, the hyaline cartilage has some ability of bending and it has more resistant to the load and weight forces acting on it and ability of bending than the elastic and fibrous cartilage. Thus, the present cartilaginous paraglossale of the hyoid skeleton of rock dove is able to resist load and weight forces acting on the free portion of the tongue during the passage of heavy food items. Similar observations were made in Columba livia, Duculaaenea, Duculabadia and Gallinula chloropus meridionalis (Bhattacharyya, 1980; Zweers, 1982; Shawki \& Ismail, 2006), and in Bubulcus ibis (Shawki\& Abdel-Rahmaan, 1998), but are missing in other birds like Streptoplia decaocto where the paraglossale is a bony element (Shawki \& Al-Jalaud, 1994a). The basihyale is composed of an anterior bony and posterior cartilaginous element. While in most bird such as Herring gull, chicken and common moorhen the basihyale is a bony (Shawki\& Al-Jalaud, 1994a; Homberger \& Meyers, 1989; Shawki\& Ismail, 2006). The dorsal surface of the bony basihyale provides the sites of origin for the muscles, usually along its longitudinal crest and the posterior cartilaginous is plate-like which bears a triplet of concave articulation surfaces. Thus, this articulation allows the movement to be up and down. The urohyale is a cylindrical bony skeletal element with a short cartilaginous process, in addition, the urohyale supports the posterior region of the preglottal area and the anterior half of the larynx. While many authors stated that the basihyal and urohyale of common moorhen are fused together and represent the supportive elements of the preglottal area, as well as the laryngeal mound (Shawki \& Ismail, 2006). The apical end of the bony part of the urohyale 


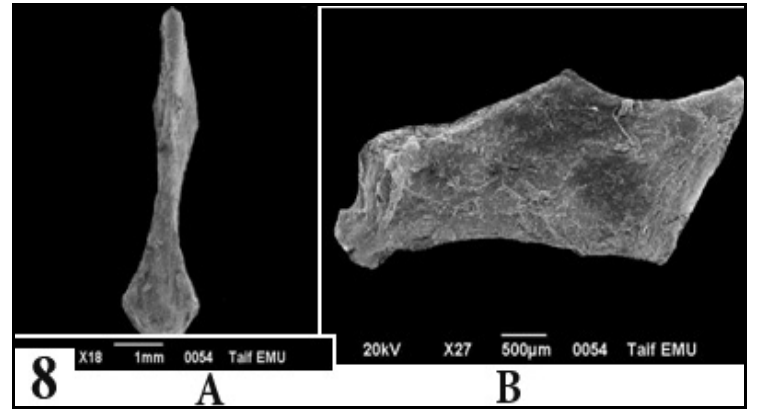

Fig. 8: Scanning electromicrograph of the dorsal surface of the Basihyale (A) and the lateral surface of the Basihyale (B) of the hyoid skeleton of the tongue of the rock dove. $18 \& 27 \mathrm{X}$.

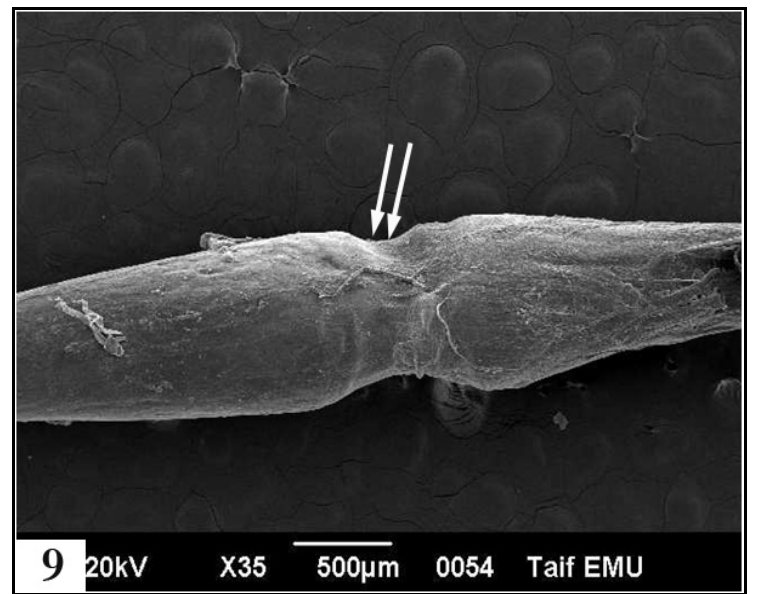

Fig. 9: Scanning electromicrograph of the lateral surface of the ceratobranchiale of the hyoid skeleton of the tongue of the rock dove showing via a synchondrosis $(35 \mathbf{x})$

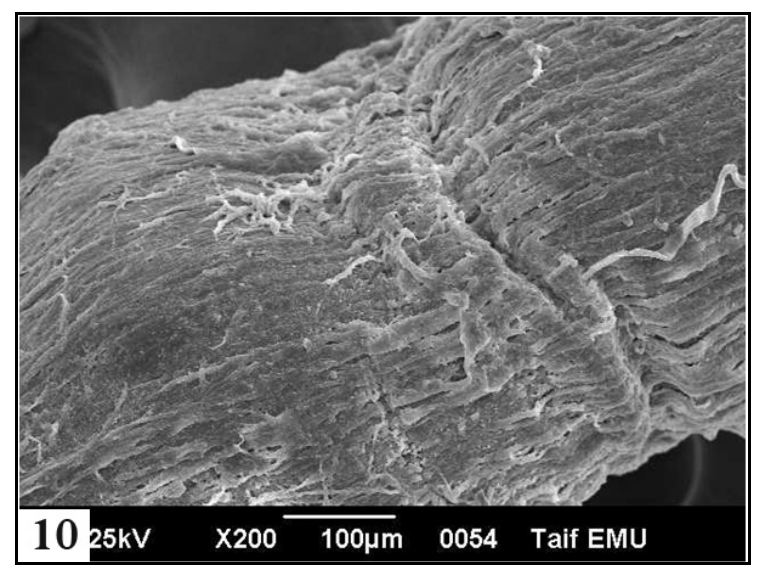

Fig. 10: Scanning electromicrograph of the dorsal surface of the via a synchondrosis of the hyoid skeleton of the tongue of the rock dove showing its cover collagen fibers (200x). is fused to the basihyale in the chicken (Homberger \& Meyers, 1989). The present results showed that ceratobranchiale is composed of elongated rod-like bony element, similar in chicken and Herrin gull (Homberger \& Meyers, 1989; Shawki \& Al-Jalaud, 1994a). It should be noticed that such synchonodrosis was observed in previous investigation of the hyoid skeleton, but it is found between two bony elements (Zweers, 1982; Battacharyya, 1980; Homberger \& Meyers, 1989; Shawki, 1995; Shawki \& Al-Jalaud, 1994a,b; Shawki \& Abdel-Rahmaan, 1998). The results obtained are compatible with these findings. In common moorhen, this synchondrosis connects bony and cartilaginous elements (Shawki \& Ismail, 2006). The epibranchiale consists of a proximal bony element and a distal cartilaginous one, this is in accordance with previous reports (Zweers, 1982; Homberger \& Meyer, 1989; Shawki \& Al-Jalaud, 1994a; Shawki \& Ismail, 2006). The different structural elements of the hyoid skeleton move along each other, resulting in the mobility of the tongue itself. The present work showed that there is a joint between paraglossal and basihyal. This means that the tongue is allowed to roll to right to left and back. The basihyal-urohyal joint and ligaments can clearly resist both heavy push and strong pull from caudal and rostral. Also, "lever" action from dorsal or ventral will be resisted by the urohyal and the bilateral bilateralbasihyal-ceratobr-anchial joints resist caudolateral push from both ceratobranchials and rostral push from the basihyal and the joint between ceratobranchial and epibranchial constitute what is known as the synchondrosis this is in agreements with Zweers (1982).

In conclusion, this study has demonstrated that the hyoid skeleton of the rock dove consists of three axial unpaired elements and a paired hyoid horn. The hyoid skeleton has Joints and ligaments to allow the hyoid elements to rotate from dorsal to ventral, from lateral to medial and from rostral to caudal, and to rotate along their axes. This may be adaptation to the bird's habitat and mode of feeding.

\section{Acknowledgement}

We would like to thank Deanship of Scientific Research (DSR), King Abdulaziz University, Jeddah, for their kind help and providing the necessary facilities for the preparation of the paper. This work would not have been possible without the generous assistance of DSR.

\section{References}

Bhattacharyya BN (1980) The morphology of the jaw and tongue musculature of the common pigeon, Columba livia, in relation to its feeding habits. Proc Zool Soc Calcutta 31: 95-127. 
Bock WJ (1974) The avian skeleton muscular system in Avian biology (eds) D S. Farner and JR King. New York. London Academic Press. 4: 119-257.

Bock W J (2001) Functional morphology of the woodpecker feeding apparatus, in "Dutta HM \& Datta Munshi, JS, (eds) Vertebrate functional morphology". Horizon of Research in the $21^{\text {st }}$ century, 295-313.

Burton PJK (1974) Jaw and tongue features in Psittaciformes and other orders with special reference to the anatomy of the tooth billed pigeon (Didunculus strigirostris). J Zool (Lond) 174: 255276.

El-Beltagy AM (2013) Comparative studies on the tongue of whitethroated kingfisher (Halcyon smyrnensis) and common buzzard (Buteo buteo). Egypt Acad J Biol Sci 4: 1-14.

Elsheikh EH, Al-Zahaby ShA (2014) Light and scanning electron microscopic study of the tongue in the hooded crow (Aves: Corvus corone cornix). J Basic Appl Zool (withdrawn). .

Erdogan SH, Sagsoz S, Akbalik ME (2012) Anatomical and histological structure of the tongue and histochemical characteristics of the lingual salivary glands in the Chukar Partridge (Alectoris chukar, Gray 1830). British poult Sci 53: 307- 315.

Homberger DG, Meyers RA (1989) Morphology of the lingual apparatus of the domestic chicken, Gallus gallus, with special attention to the structure of the fascia. Am J Anat 186: 217-257.

Homberger DG (1986) The lingual apparatus of the African grey parrot Psittacus erithacus, Linn. (Aves, Psittacidae): Description and theoretical mechanical analysis. Ame Ornith Union (AOU), 39: 1-233.

Humason G L (1972) Animal tissue techniques. $3^{\text {rd }}$ edn. W. H. Free Comp. San Francisco. 180-182.

Igwebuike UM, Eze UU (2010) Anatomy of the oropharynx and tongue of the African pied crow (Corvus albus). Veterin arhiv 80: 523-531.

Korzoun LP, Erard C, Gasc JP (2001) Distinctive morphofunctional features of the bill and hyoid apparatus of turacos (Aves, Musophagidae): relations with frugivory. CR Acad Sci III 324: 96577.

Minoru I (1976) Differential staining of cartilage and bone in fetal mouse skeleton by alcian blue and alizarin red s. Cong Anom 16: 171-173.
Parchami A Dehkordi FRA (2013) Light and electron microscopic study of the tongue in the in the White-eared bulbul (Pycnonotus leucotis). Iran J Vet Res, 14: 9-14.

Parchami A, FatahianDehkordi RA, Bahadoran S (2010) Scanning electron microscopy of the tongue in the golden eagle Aquila chrysaetos (Aves : Falconiformes : Accipitridae). J Zool 5(4): 257-263.

Richards LP, Bock WJ (1973) Functional anatomy and adaptive evolution of the feeding apparatus of the Hawaiian honey creeper, Genus Loxops (Drepandidae). American Ortnotholoists Union (AOU). 15: 1-173.

Shawki NA, Al-Jalaud NA (1994b) Functional morphology of the lingual apparatus of the herring gull, Larusargentatus. Egypt. J Anat 17: 79-108.

Shawki NA, Ismail AI (2006) Functional morphology of the lingual apparatus of the common moorhen, Gallinula choropus meridionalis( Aves: Rallidae). 1- the lingual skeleton. Egypt J Zool 46: 41-57.

Shawki NA, Abd El-Rahmaan GH (1998) Functional morphology of the hyoid skeleton of the cattle egret, Bubulcus ibis. J Egypt Ger Soc Zool 26(B): 91-111.

Shawki NA, Al-Jalaud N A (1994a) Structure and function of the lingual apparatus of the collared dove, Sterptopelia decaocto. Egypt J Anat 17: 5178 .

Shawki NA (1995) A correlation between the functional morphology of the lingual apparatus and feeding behavior of the Egyptian black kite, Milvus migrans aegyptius. Egypt J Anat 18(2): 179-209.

Shawki N, Ismail AI (2006) Functional morphology of the lingual apparatus of the common moorhen, Gallinula choropus meridionalis( Aves: Rallidae). 2- the lingual muscles. Egypt J Zool 46:59-80.

Zweers GA (1982) Pecking of the pigeon (Columba livia). Behaviour 81: 173-230.

Zweers GA (1974) Structure, movement and myography of the feeding apparatus of the mallard, Anas platyrhynchos L. Neth J Zool 24: 323-467.

Zweers, GA, Gerritsen, AFC, Kranenburg-Voogd PJ (1977) Mechanics of feeding of the mallard (Anas platyrhynchos L., Aves, Anseriformes). In: Hecht MK., Szalay FS. (eds) Contributions to Vertebrate Evolution. 